\title{
Customer-Oriented and Eco-friendly Networks for Health Fashionable Goods - The CoReNet Approach
}

\author{
Américo Azevedo ${ }^{1}$, João Bastos ${ }^{1}$, António Almeida ${ }^{1}$, Carlos Soares ${ }^{1}$, \\ Nicola Magaletti ${ }^{2}$, Enrico Del Grosso ${ }^{2}$, Dieter Stellmach ${ }^{3}$, Marcus Winkler $^{3}$, \\ Rosanna Fornasiero ${ }^{4}$, Andrea Zangiacomi ${ }^{4}$, and Andrea Chiodi ${ }^{5}$ \\ ${ }^{1}$ INESC Porto \& Faculdade de Engenharia da Universidade do Porto, \\ Rua Doutor Roberto Frias S/N, 4200-465 Porto, Portugal \\ \{ala, joao.bastos, antonio.henrique\}@fe.up.pt, csoares@fep.up.pt \\ ${ }^{2}$ TXT e-Solutions SPA, Via Frigia 27, 20126 Milano, Italy \\ \{nicola.magaletti, enrico.delgrosso\} @txt.it \\ ${ }^{3}$ DITF Denkendorf - Centre for Management Research, Koerschtalstrasse 26, 73770 \\ Denkendorf, Germany \\ \{marcus.winkler, dieter.stellmach\} dditf-denkendorf.de \\ ${ }^{4}$ ITIA-CNR -Institute of Industrial Technologies and Automation -National Council of \\ Research, Via Bassini 15, 20133 Milano, Italy \\ \{rosanna.fornasiero, andrea.zangiacomi\}@itia.cnr.it \\ ${ }^{5}$ SYNESIS - Viale Fulvio Testi, 128, Cinisello Balsamo, Milano, Italy \\ andrea.chiodi@synesis-consortium.eu
}

\begin{abstract}
The design, production and distribution of small series of health fashionable goods for specific target groups of wide impact in terms of market for the European industry as elderly, disables, diabetics and obese people represents a challenging opportunity for European companies which are asked to supply the demand with affordable price and eco-compatible products. Added to this challenge, textile, clothing and footwear manufactures seek for innovative collaborative networking solutions that could provide an entire digital life-cycle for the products and services required by the market. Aligned with this need, the EU CoReNet project aims to design and develop a new smart collaborative consumer-driven framework with the related services and components. This paper addresses the multidisciplinary complexity of customer-oriented and eco-friendly networks for health fashionable goods in particular addressing business requirements analysis, value chain issues, coplanning production and co-design topics in collaborative business processes tailored for high variability of the consumers demand and expectations.
\end{abstract}

Keywords: Collaborative Networks, Value Chain, Business Intelligence, Collaborative Framework.

\section{Introduction}

In recent years it is emerging at industrial level an adoption of collaborative strategies addressing the small series production of high-customized complex products. This is particularly relevant for health fashionable goods for specific target groups. In fact, 
consumer needs and expectations of specific target groups - such as elderly, obese, disabled, or diabetic persons- are arising as challenging opportunities for European companies which are asked to supply small series of innovative and fashionable goods of high quality, affordable price and eco-compatible. In order to design, develop, produce and distribute such products, a new framework and related components of collaborative networking are need to be developed, enabling the product to stay as long as possible digital to produce on-demand.

Research is necessary in many topics like: a) consumer integrated collaborative eco-oriented design, b) a radical renewal by the adoption of Rapid Manufacturing and Business Intelligence technologies; and c) the overall integration and co-ordination of business processes and information exchange by a set of new (web)services for network design and ad-hoc (re-)configuration, for real-time planning, forecasting and replenishment, and for tracking and tracing of ecology and quality.

This paper addresses the multidisciplinary complexity of customer-oriented and eco-friendly networks for health fashionable goods in particular concerning main collaborative business processes tailored on customized environment as well as able to respond to the high variability of the consumers demand and expectations.

\section{Foundations and Research Topics}

The emergence of global markets has forced the European Manufacturing Industry, SMEs in particular, to adapt to a new competitive environment in order to proactively respond to challenging market requirements with increased responsiveness and flexibility. This reality is intensified by the fact that consumer goods, in particular fashion products as clothing and footwear have in the last years been facing an increased number of seasonal collections. Moreover the mass customization paradigm requires that companies are ready to produce small batches (till one-of-a-kind product for mass market) to satisfy customer requirements.

Other related aspects are not only connected with social phenomena's such as ageing, increased obesity and disabled people but also with the growing sensitivity towards eco-friendly products. All these issues pose a challenge for TCFI (textile, clothing and footwear industry) manufacturers: how they can address consumers demand for personalization and value adding of harmonized products not only in terms of aesthetics, but also in terms of health, innovative functionalities and environmental impact?

Nowadays there is a clear need for health fashionable consumer goods, since customers want to be fully satisfied both under the point of view of their look and their health. This need generates a very distinctive type of demand, based on small lot series and fast delivery, forcing companies to change their manufacturing philosophy. It is no longer possible to deal with long transportation times of materials and components or extended lead times in manufacturing services to face this new demand paradigm.

Indeed, addressing this new type of customer demand groups as main target, it is necessary to develop new collaborative supply chain solutions based on cost effective, social compliant and eco-efficient design and production of customized products that fully satisfy the customers considering their health issues as well as their desire for fashionable products. 


\subsection{Value Chain Issues}

As previously underlined, once products are becoming less standardized as customers are demanding custom-tailored options, one of the major challenges faced by TCFI organizations is the demand for increasingly levels of value in terms of responsiveness and shorter cycle times for production and delivery of newly developed products at lower prices. This calls for a supply chain that is quick, accurate, and provides top-quality products and customer support at different levels and steps.

As a consequence products are becoming more complex, presenting a greater variety of configurable options and must be tailored to a greater number of smaller market "niches". Therefore, in many market segments, only those firms that present the ability to "mass-customize" are able to success.

The traditional view of the customer as a passive actor in the value chain is rapidly changing. The continuous transfer of power in the supply chain, from the producer to the consumer, is forcing the conventional approach to become less and less appropriate. As Christopher argues: "in the present, instead of designing supply chains from the 'factory outwards' the challenge is to design them from the 'customer backwards" "[1]. With this new reality, the consumer should not be at the end of the supply chain but at its start, forcing to a change of philosophy from supply chain management to demand chain management. In this new vision, there is a philosophical difference between supply chain management and what Christopher call 'demand chain management'. This new concept is focused in creating a market-driven supply chain and starts by fully understanding the value that customers seek in the market in which the firm competes. This customer perception will enable the identification of the market segments and subsequently the value proposition by translating customer requirements into an offer of customized product and services. The final step is to integrate the customer value with an effective supply chain network strategy that addresses the demand with intelligent approaches.

\subsection{Business Intelligence in Collaborative Networks}

To be able to quickly respond to changes in the demand, companies must be able to continuously monitor the behavior of their customers. This can be done with Business Intelligence tools [2]. These tools use data that represent the behavior and preferences of customers obtained not only from transactional systems (e.g., orders) but also from other sources where they express their opinions (e.g., social networks).

These data are then stored in a Data Warehouse (DW) [3], which is a database designed for decision support and not for operational purposes. From these technologies, designers can automatically extract patterns from the behavior of customers using OLAP (OnLine Analytical Processing) tools, dashboards as well as Data Mining (DM) techniques [4]. From the DM methods, that can be useful for designers, two main approaches can be identified: clustering, to identify subgroups of customers with homogeneous behavior, and association, to identify emerging trends (e.g. recently, shirts with classic design typically also have single cuffs).

Models supported by these methods can be applied to improve production planning and supply chain management (e.g., anticipating trends in product demand and, 
consequently, in raw material needs), to design new products (e.g., anticipating what product features may be most successful in the coming seasons) as well as sales and marketing (e.g., customizing catalogs and websites for different customer profiles).

\subsection{Co-planning Production in Collaborative Networks}

Small series and customized products require totally different supply networks structures, where each company is specialized in a specific manufacturing phase of a product or a market segment. In this context, and following the approach described, a supply network should be configured for each customer order and tend to include a small number of skilled companies. The key selection criteria should be the ability to perform the required operations for the desired delivery date, with the expected cost. In practice these scenarios will be characterized by a very large number of small orders, each of them having different partner companies, based on their availability and capabilities. In this context co-planning and control will be required to optimize the production plans that result, on a first iteration, from the configuration (or set up) of the supply network for each order.

For those companies, at the end of the design and development process, where all the items belonging to a specific collection and the related basic elements have been defined (for example, 2D/3D models, Part Programs for cutting, printing and any other automation step), the products are ready to be proposed for sales.

For the addressed consumer categories, a "configuration space" may be provided to define the final version of product, without including the "critical" components (for example the fabrics and yarns for garments, the last and sole for the shoes, etc.) that must be kept absolutely standard for the higher number of different models, since this level of personalization would imply costs not acceptable for small series.

Beside the early phases for the design and development of the collection, once the sales have been closed and the product completely defined and configured, along with the measures, quantities and due dates, all the complete set of information required for the actual production can be finally defined (final BOM, accessories, etc.) and the production orders $(\mathrm{PO})$ can be generated for a specific customer order. During this phase it is possible to identify the Supply Chain specification (design and formation) for a specific customer order, that implies to have identified all the suppliers and partners in charge of carry out all the external activities, assigned the whole set of operations associated to a specific product and finally obtained all the information and data needed for the planning activities.

One of the most critical aspects during the PO execution is the management of the external activities that may be strongly different for each product. Therefore, during the PO execution is strongly required that manufacturer and partners could interact and share information, exchange documents and take decisions.

For this specific purpose, this paper addresses the importance of flexible IT services supporting collaborative planning that should engage the manufacturer and any partner to be involved on specific order basis. The main objective is to enable the planning of POs assigned to any partner and support the related info and document management. 


\subsection{Co-design and Sustainability}

Collaborative design tools empowers the consumers to design their own products by providing them the ability to collaborate in an informed design process not only regarding aesthetics, prices and delivery times, but also resources consumption and social responsibility. In line with this, to implement sustainability parameters in the design phase rely on the synchronization of the design along the supply chain. In product (co-)design commercial tools, the product design stage is seen as a unique phase to be performed by designer, eventually based on some indications/sketches defined by the consumer and the consumer interaction always take place only in terms of product configuration. However due to the change of power from companies to customers, co-design should not only be supported through the usual consumerdesigner interaction, providing the consumer with dedicated mechanisms for indications on product style and for simplified direct modification of product design, but also through co-design collaborative mechanisms along the supply chain.

Indeed, nowadays stakeholders collaborating to product definition (especially shoes) are today acting in a fragmented supply chain, counting more than 20 steps including materials and components subcontractors. In such a context, product engineering is spread between different actors and interoperability is still an open issue. Therefore, in this paper it will be addressed such a gap by providing interoperability mechanisms to collect internal CAD data, orientate them and exchange product design information with PDM systems of component suppliers along the chain and recollect then intermediate part engineering in the central CAD.

Concerning sustainability aspect, first of all it has to be underlined that garments and shoes are complex products in terms of their environmental impacts. Therefore a pressing matter related with this issue involves the track and trace retrieval of information related to each product and its production process (to any level of depth along the supply chain) by relevant stakeholders, along the whole product life cycle to enable products and related components traceability.

\section{CoReNet Approach}

The proposed CoReNet (Customer-Oriented and Eco-friendly Networks for Health Fashionable Goods) approach [5], intends to support textile, clothing and footwear companies in the implementation of new models for small series production for health and fashionable goods following the Competitive Sustainable Manufacturing (CSM) paradigm [6] and current initiatives of European Technological Platforms like Manufuture [7] and Footwear. The project intends to support the whole value chain to get and manage consumer data to investigate its needs; involve consumer into design and product configuration phases; exchange consumer data through adequate data models and secure systems; manage the collaboration with suppliers in order to plan and distribute on time; implement innovative manufacturing technologies; deliver timely the product to customer; and monitor the quality and sustainability of products.

Sustainability issues will be assured by the exploitation and implementation of technologies able to exploit the emergent and pervasive infrastructure of the Semantic Web, joined to an effective adoption of state of the art RFID and sensor technologies. 
With this approach, consumers and the whole distribution system will be able to verify the quality of products before their purchase and during their utilization. On the other side, designers will be allowed to model their product after a precise connotation of all the chosen product's components and producers will be able to verify such characteristics along each step of production and supply.

\subsection{Consumer Target Group Analysis}

In the case of CoReNet project the target is mainly on specific market segments where it is necessary to find the right trade-off between healthy and fashionable features of products for disabled, diabetic, obese and elderly people. As previously underlined, products should be based not only on fashion trends but may cover different kind of requirements coming from customers, both based on aesthetic and on functional and on health needs.

The analysis of the target groups' requirements which is part of this work is based on existing literature and on field questionnaires made to European people belonging to these categories. What turned out is that these target groups represent a share of the market which is getting larger and larger, asking for products to fulfill their requirements in terms of improved comfort and wearability, like to protect the body from regular environmental impact (e.g. heat, cold, water, humidity) in a high comfort and high quality. This means for TCFI companies to refocus design and production of their clothing and shoe models based not only on fashion requirements but also on other features which need to be taken into consideration from the design phase changing the approach to product conception.

\subsection{Business Requirements Analysis}

The CoReNet project aims at enterprise interoperability with a special focus on the development of a new holistic framework, consisting of a set of methods, tools and technologies to support collaborative networks addressing consumer-oriented market segments demand for sustainable small series of fashionable products. In order to identify the functional requirements for this framework, a set of business requirements analysis was performed in key industrial players of TCFI supply chain. This comprehensive analysis allowed the identification of functional requirements (see fig. 1) and use case scenarios (overlapping both the footwear and clothing scenarios) relevant to the definition of the CoReNet proposed reference model.

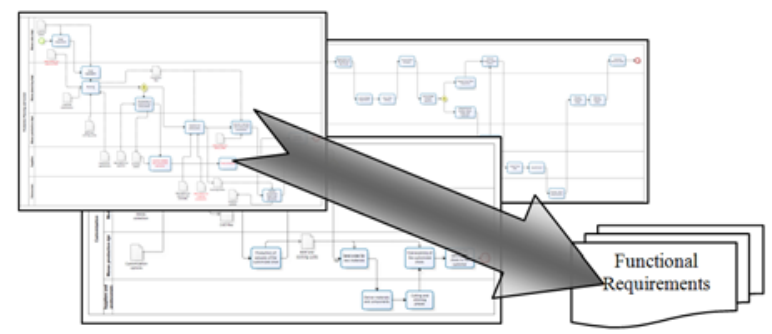

Fig. 1. Business Requirements gathering 


\subsection{Proposed Reference Model}

The Reference Model proposed is based on mapping TCFI processes at three levels: strategic, tactic and operative according to three perspectives (cf. Fig.2):

Organizational Perspective: Through the proposal of innovative production paradigms based on new concepts that go beyond-lean approaches addressing the agile manufacturing concept. The process planning and configuration of the supply networks is achieved through collaboration mechanisms generating a virtual organization model fit to provide the required productive resources. Also the formalization of interaction processes with customer requirements and needs will complete the design of the value chain.

ICT Perspective: It is related with the required infrastructure that supports the services, methods and tools necessary for the network operation. This infrastructure maps the information and ICT services necessary for networking management during the different processes identified (from design, to product configuration, to production planning, to production to delivery).

Knowledge Perspective: The knowledge perspective of the reference model highlights both the available knowledge and business intelligence in the network and the required knowledge at other places along the network. This covers all different kinds of knowledge from partner competences to knowledge about material properties or machinery availability and process capabilities.

In this context, the specific objective of new research shall be to increase significantly the sustainability of value creation of small series health fashionable consumer goods and in particular of footwear and accessories, for emerging social niches like elderly, obese, diabetics and disable people, by systemic/coordinated intraand inter-sector networking of producers/service providers using cutting-edge (digital and) production technologies as well as innovative organizational models based on cross-supply network integration through the major breakthrough innovations which are complementary each other.

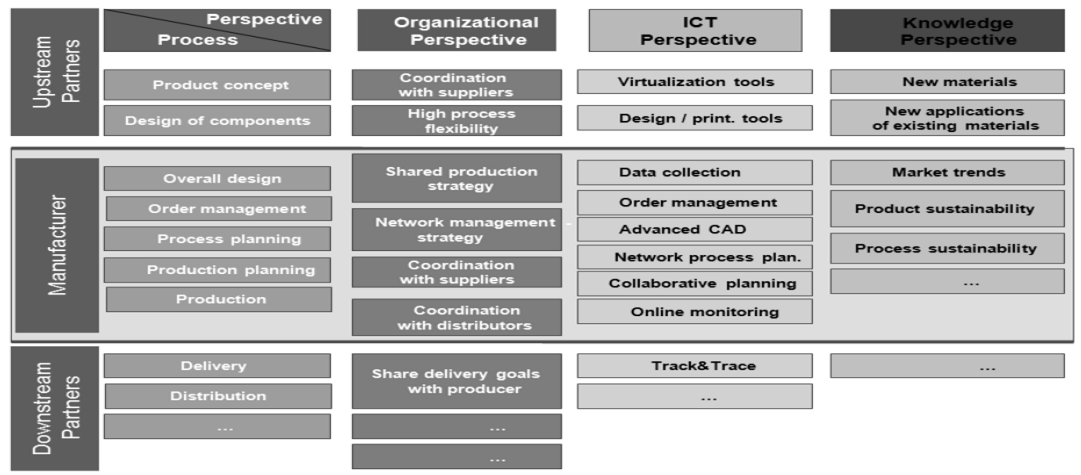

Fig. 2. CoReNet Proposed Reference Model 
The proposed Reference Model will be applicable both to companies producing customized goods according to the traditional framework where most of the production is kept internally (i.e. only minor processes are externalized like production of components) and to companies doing their business on online sales, externalizing most of the other processes. This requires different levels and means of collaboration in the three different perspectives (organizational, ICT and knowledge) which need to be investigated.

\section{Conclusions and Further Research}

The ongoing European project "Customer-oriented and eco-friendly networks for healthy fashionable goods (CoReNet)" aims to provide TCFI companies with the tools and methods to face the challenge of working in demand-driven and customer oriented collaborative networks.

Until now the project research work allowed the definition of a Reference Model that set up the foundations for the development of future technologies and tools that support network operation. The following phases include the instantiation to specific companies' requirements of the reference model according to their business model in order to support them in the path to small series production of healthy products. The model will be evaluated and improved in the CoReNet project together with the industry partners and the customers.

Acknowledgments. The research leading to these results has received funding from the European Union's Seventh Framework Programme (FP7/2007-2013) under grant agreement $n^{\circ}[260169]$.

\section{References}

1. Christopher, M.: Logistics and supply chain management - Creating Value-Adding Networks, 3rd edn. Prentice Hall, Englewood Cliffs (2005)

2. Lo, W., Hong, T., Jeng, R.: A framework of E-SCM multi-agent systems in the fashion industry. International Journal of Production Economics 114, 594-614 (2008)

3. Kimball, R., Reeves, L., Ross, M., Thornthwaite, W.: The Data Warehouse Lifecycle Toolkit, 2nd edn. Practical Techniques for Building Data Warehouse and Business Intelligence Systems. Wiley, Chichester (1998)

4. Han, J., Kamber, M.: The Data mining: concepts and techniques. Morgan Kaufmann Publishers Inc., San Francisco (2000)

5. Fornasiero, R., Chiodi, A., Carpanzano, E., Carneiro, L.: Research issues on Customeroriented and eco-friendly networks for health fashionable goods. In: Ortiz, Á., Franco, R.D., Gasquet, P.G. (eds.) BASYS 2010. IFIP AICT, vol. 322, pp. 36-44. Springer, Heidelberg (2010)

6. FoF-PPP: Factories of the Future: Public, Private Partnership, Strategic Multi-annual Roadmap (2009)

7. Manufuture, Strategic Research Agenda (2006) 